\title{
O lugar do nutricionista nos Núcleos de Apoio à Saúde da Família
}

\author{
The place of nutritionist in the Support Centers \\ for the Family Health Strategy
}

Diana Cris Macedo RODRIGUES'

Maria Lúcia Magalhães BOSI ${ }^{1}$

\section{Objetivo}

Este estudo objetiva compreender percepções e experiências de nutricionistas atuantes em Núcleos de Apoio à Saúde da Família acerca de sua inserção na Estratégia Saúde da Família.

\section{Métodos}

Trata-se de uma investigação orientada pela abordagem qualitativa, ancorada em fundamentos epistemológicos da vertente crítico-interpretativa. O material empírico resultou da articulação entre entrevistas em profundidade e observações livres, realizadas junto a nutricionistas inseridos nos Núcleos de Apoio à Saúde da Família de Fortaleza, Ceará. O processamento e categorização do material empírico evidenciou três eixos centrais, dos quais um, "O nutricionista na Estratégia Saúde da Família", foi eleito foco deste artigo.

\section{Resultados}

Os profissionais têm estruturado seu processo de trabalho assumindo majoritariamente uma prática individualizante e tecnicista, com escassa reflexão acerca de sua atuação. A realização de atividades em âmbito coletivo, intentando prevenir doenças, foi considerada a principal atribuição do Núcleo de Apoio à Saúde da Família. Grande parte dos informantes concebeu o lugar do nutricionista na prevenção e tratamento de doenças e agravos relacionados à alimentação, por meio de uma educação nutricional voltada à racionalização de recursos. Entretanto, ainda que minoritariamente, experiências em curso revelam outras formas de perceber o lugar do nutricionista, remontando à realização do cuidado em saúde, de forma coerente com os princípios do Sistema Único de Saúde.

\section{Conclusão}

Nos achados preponderam posturas profissionais pouco alinhadas aos princípios basilares do Sistema Único de Saúde e às políticas de Segurança Alimentar e Nutricional, apontando incongruências entre estas e as necessidades de saúde da população.

Termos de indexação: Atenção Primária à Saúde. Nutricionista. Pesquisa qualitativa.

${ }^{1}$ Universidade Federal do Ceará, Faculdade de Medicina, Departamento de Saúde Comunitária. R. Prof. Costa Mendes, 1608, Bloco Didático, $5^{\circ}$ andar, Rodolfo Teófilo, 60430-140, Fortaleza, Ceará, Brasil. Correspondência para/Correspondence to: MLM BOSI. E-mail: <malubosi@ufc.br>. 


\section{A B S T R A C T}

\section{Objective}

This study aimed to understand perceptions and experiences of nutritionits who work at the Support Centers for Family Health about their inclusion in the Family Health Strategy.

\section{Methods}

This investigation was guided by a qualitative approach, grounded in epistemological foundations of critical and interpretative aspects. The empirical material resulted from the coordination between the in-depth interviews and the free observations conducted with the dieticians inserted in Support Centers for Family Health, Ceara.

\section{Results}

The processing of the empirical data revealed three central axes of which the theme "The Nutritionits in the Family Health Strategy" was elected as the focus of this article. The professionals have structured their work process mostly taking individualizing and technicist practices, with little reflection on their performance. Conducting activities in a community basis intending to prevent diseases was considered the primary responsibility of the Support Centers for Family Health. A big part of informants conceived the place of nutritionist in the prevention and treatment of diseases and disorders related to food, through a rationalization of resources focused on nutrition education. However, even though a minority, experiences reveal other ways of perceiving the place of nutritionits, reassembling the realization of health care consistent with the principles of the Unified Health Care System.

\section{Conclusion}

The results show professional attitudes little connected with the basic Unified Health Care System principles and policies for food and nutrition security, pointing out inconsistencies between these and the real health needs of the population.

Indexing terms: Primary Health Care. Nutritionist. Qualitative research.

\section{N T R O D U ÇÃ O}

A partir da década de 1970, a Atenção Primária à Saúde (APS) ganha relevância no cenário internacional como uma importante estratégia de provisão de cuidados básicos em saúde. Tal estratégia tem como marco a Conferência Internacional de Alma Ata, realizada em 1978, a qual se tornou referência nas discussões acerca das políticas públicas de saúde em todo mundo, reafirmando o direito à saúde como direito humano fundamental' .

O cenário em que floresceu o debate acerca da APS foi marcado pela crise no setor saúde vivenciada por diversos países, na qual o modelo médico hegemônico foi apontado como um dos principais indutores. A crescente elevação dos custos em saúde, aliada à insuficiente repercussão positiva destes na qualidade de vida e nível de saúde das populações, colocou em evidência a necessidade de se estruturarem novos modelos assistenciais. Nesse contexto, a APS surge como importante estratégia de universalização do acesso à saúde ${ }^{1,2}$.

As primeiras iniciativas brasileiras de APS buscaram inspiração no referencial de Alma Ata. Entretanto, com o advento do Sistema Único de Saúde (SUS), esse referencial diminuiu gradativamente sua influência'. Os princípios do SUS e as diretrizes desse sistema faziam oposição à perspectiva difundida por agências multilaterais na América Latina, nomeada de APS seletiva, entendida como uma atenção à saúde reduzida a um pacote de ações de combate a patologias previamente selecionadas, desconsiderando os determinantes sociais das doenças, a infraestrutura de saúde pré-existente e a participação comunitária².

Em 1994, a Estratégia Saúde da Família (ESF) foi proposta pelo Ministério da Saúde como modelo prioritário para estruturação da APS brasileira, opondo-se à APS seletiva adotada em outros países. Todavia, é importante assinalar que essa estratégia não se configura como o único 
modelo em curso, uma vez que, devido às dimensões continentais, diversidades loco-regionais e desigualdades sociais presentes no país, coexistem diferentes formas de estruturação de serviços de saúde, incluindo os modelos tradicionais de assistência à saúde?

A Estratégia Saúde da Família surge em resposta à crise do modelo biomédico, buscando materializar o ideário do SUS, já que intenta reafirmar um novo paradigma assistencial. A operacionalização da ESF consiste na inserção de equipes de Saúde da Família (SF), compostas por médicos, enfermeiros, agentes comunitários de saúde e equipe de saúde bucal em unidades básicas de saúde, as quais têm responsabilidade sanitária por uma determinada população ${ }^{3,4}$.

Com o intuito de apoiar a inserção da ESF no território brasileiro, bem como qualificar e ampliar as intervenções realizadas pela estratégia, em 2008, o Ministério da Saúde criou os Núcleos de Apoio à Saúde da Família (NASF). A proposta trata da incorporação de uma equipe composta por um leque mais amplo de categorias profissionais da área da saúde, com o objetivo de fornecer retaguarda especializada às equipes de SF, ampliando assim a resolubilidade das ações ${ }^{5}$. Para a concretização desse objetivo, o processo de trabalho do NASF embasa-se em novas ferramentas de gestão do trabalho e pressupostos teórico-metodológicos, buscando superar a fragmentação da atenção à saúde.

O conceito de "apoio matricial" é central na proposta, na qual os profissionais do NASF configuram-se como apoiadores matriciais das equipes de SF. Os documentos oficiais aludem à realização desse apoio mediante duas dimensões centrais - assistencial e técnico-pedagógica -, em interação na dinâmica do trabalho ${ }^{6}$.

O apoio matricial e a equipe de referência (no caso, a equipe de SF) são concebidos como "arranjos organizacionais e uma metodologia para a gestão de trabalho em saúde, objetivando ampliar as possibilidades de realizar-se clínica ampliada e integração dialógica entre distintas especialidades e profissões"7 (p.400). Assim, a tecnologia do apoio matricial baseia-se na realização de um trabalho eminentemente interdisciplinar, mediante o estabelecimento de espaços propiciadores de diálogo que se fazem necessários a fim de possibilitar a condução compartilhada dos problemas, bem como a construção de estratégias e diretrizes de trabalho ${ }^{7}$.

A organização do processo de trabalho do NASF prevê ainda a realização de ações de saúde referenciadas por nove áreas estratégicas, a serem desenvolvidas por todos os profissionais atuantes na ESF, entre elas a área de alimentação e nutrição ${ }^{6}$. A incorporação das ações de alimentação e nutrição na ESF contribui para a integralidade da atenção à saúde, uma vez que se configura como parte essencial do cuidado integral em saúde nas Redes de Atenção à Saúde (RAS), devendo fornecer respostas às principais demandas assistenciais da ESF e qualificar o cuidado em saúde propiciado pela RAS ${ }^{8}$. Ademais, a incorporação constitui-se elemento estratégico na atuação do setor saúde, com vistas à promoção da Segurança Alimentar e Nutricional (SAN) e sua articulação com o Sistema Nacional de Segurança Alimentar e Nutricional $(\text { SISAN })^{9}$.

No intuito de fortalecer e ampliar o escopo dessas ações, o NASF propõe a inserção do nutricionista entre os membros de sua equipe. Assim, apesar da inclusão desse profissional na APS em iniciativas anteriores em municípios brasileiros ${ }^{10}$, a proposta permitiu uma expressiva incorporação do nutricionista neste âmbito de atenção, conformando um importante lócus de sua atuação no SUS.

Consoante a proposta, o nutricionista no NASF deve estruturar seu fazer buscando um trabalho interdisciplinar voltado à integralidade do cuidado em saúde, mediante o compartilhamento de saberes, práticas e responsabilidades com as equipes referenciadas e demais profissionais. A proposta de organização do trabalho no NASF desafia a histórica atuação da categoria, centrada em aspectos técnicos, de foco individual, direcionada preponderantemente ao âmbito da execução de atividades, a qual marcou sua inser- 
ção em outras políticas e programas sociais ${ }^{11,12}$. Não obstante, ressalta-se o fortalecimento da atuação do nutricionista em esferas de gestão e planejamento do SUS nas últimas décadas, principalmente em âmbito federal, o que potencializa a construção e consolidação de uma prática social-técnico-política do profissional, nos diversos espaços da assistência.

A inserção do nutricionista no NASF tensiona fortemente o aspecto da formação profissional para o SUS, evidenciando a necessidade de adequação curricular, já prevista nas Diretrizes Curriculares Nacionais ${ }^{13}$ publicadas em 2001. Entretanto, apesar da regulamentação com ênfase no SUS predita nos instrumentos legais, verifica-se ainda o predomínio da formação tecnicista do profissional, conforme documentado na literatura11,12,14. Em virtude disso, uma das premissas desta pesquisa é a de que o nutricionista enfrenta dificuldades na construção de sua prática na ESF.

Apesar de o lugar do nutricionista na ESF ser aludido mediante delineamentos presentes na proposta NASF, é preciso afastar-se desse pressuposto, no intuito de apreender como os profissionais efetivamente compreendem seu lugar na ESF e como vivenciam a experiência de se constituírem nutricionistas nesse novo espaço de atuação. A carência de produções acadêmicas sobre o assunto motivou o desenvolvimento deste estudo, o qual tem como objetivo compreender percepções e experiências de nutricionistas atuantes na ESF, mediante a atuação no NASF.

\section{M É TODOS}

A natureza do objeto de estudo demanda uma investigação orientada pela abordagem qualitativa. A pesquisa ancorou-se na vertente crítico-interpretativa, a qual assume a produção subjetiva vinculada ao contexto material no qual se insere, exigindo ainda que a produção do conhecimento se submeta à reflexividade em todas as etapas da pesquisa. Considera-se a reflexividade como exercício de crítica durante todo o processo de investigação científica, buscando problematizar teoricamente todas as fases do estudo ${ }^{15}$.

A pesquisa foi realizada junto aos nutricionistas inseridos na ESF do município de Fortaleza (CE) por meio da proposta NASF entre os meses de novembro/2011 a março/2012. O NASF, vale ressaltar, foi implantado no município a partir de julho de 2009. No período do trabalho de campo, dez profissionais de nutrição atuavam nos NASF do município, sendo, portanto, contemplada a totalidade dos participantes durante a obtenção das informações.

Com o intuito de acessar a produção subjetiva dos nutricionistas foi utilizada como técnica entrevistas em profundidade, realizadas individualmente, em um único momento, com cada um dos participantes, em unidades de saúde nas quais os NASF estavam inseridos. Além disso, as anotações registradas em diário de campo na ocasião das visitas, a partir de observações livres realizadas, serviram de apoio à construção das informações.

As entrevistas foram gravadas após assinatura do termo de consentimento livre e esclarecido pelos participantes e tiveram duração média de 60 minutos. Em seguida, foram transcritas na íntegra e na categorização e análise buscou-se conectar as informações obtidas no campo a perspectivas teóricas previamente discutidas, bem como a outras literaturas pertinentes ao exercício interpretativo.

A categorização do material empírico conduziu a três eixos centrais constitutivos da rede interpretativa do estudo: 1) Inserção na ESF; 2) Percepções acerca do contexto; 3) O Nutricionista na ESF. O último eixo constitui o foco da presente publicação, ainda que transversalizado pelos demais, consoante a perspectiva de rede de significação, cada eixo desdobrando-se em diferentes dimensões, conforme se verá no tópico seguinte.

O estudo foi submetido e aprovado pelo Comitê de Ética em Pesquisa da Universidade Federal do Ceará, por meio do protocolo n 271/11. 
As recomendações da Resolução 196 de 10 de outubro de $1996^{16}$, atinente aos aspectos éticos da pesquisa envolvendo seres humanos, foram obedecidas durante a pesquisa.

\section{RESULTADOS E DISCUSSÃO}

Apesar de a proposta NASF prever definições acerca da prática do nutricionista, conforme já salientado, é válido ressaltar que tal prática se encontra em construção nos diversos espaços de inserção profissional na ESF brasileira. Assim, apreender como o nutricionista percebe sua contribuição é fundamental para a discussão acerca dos posicionamentos assumidos pela categoria na consolidação do SUS e, ainda, acerca desse novo espaço de atuação. Busca-se, portanto, dialogar com percepções e experiências desses profissionais, a seguir discutidas.

Os participantes do estudo formaram-se, majoritariamente, em uma universidade pública do estado do Ceará, sendo apenas um do sexo masculino. Esse dado corrobora a literatura'11,12, que refere historicamente a elevada concentração de mulheres nessa categoria profissional, confirmando trabalhos realizados anteriormente. A idade dos entrevistados e o tempo decorrido após a conclusão da graduação foram bastante variáveis. Os participantes tinham entre 25 e 57 anos, dos quais seis possuíam dez ou mais anos de graduação; para quatro deles, o tempo de graduação era inferior a quatro anos. A média do tempo de inserção dos nutricionistas no NASF do município foi de aproximadamente 20 meses, e todas eram especialistas ou estavam cursando alguma especialização.

As falas dos entrevistados permitem depreender que o NASF e a ESF são concebidos pela maioria dos participantes como propostas voltadas à prevenção de doenças e suas complicações, sobretudo mediante atividades educativas em nível coletivo, conforme pode ser observado nos discursos transcritos nos tópicos seguintes. Nesse aspecto, torna-se interessante refletir sobre as considerações de Pilon ${ }^{17}$.
O autor defende que os problemas complexos da modernidade, inclusive os do campo da saúde, não podem ser pensados por perspectivas fragmentadas e fragmentadoras da realidade; caso contrário, incorre-se na construção de abordagens parciais e ineficazes. Assim, propõe que as questões humanas sejam tratadas por meio da abordagem ecossistêmica da qualidade de vida, composta por quatro dimensões: dimensão íntima - aspectos subjetivos dos indivíduos; dimensão interativa - relacionamento interpessoal e em grupos de referência; dimensão social - contexto político, social, econômico, cultural; dimensão biofísica -, ambientes naturais e construídos. Tais dimensões devem ser pensadas de maneira integrada, pois cada uma exerce influência sobre as demais e as modifica ${ }^{17}$.

Dessa forma, a abordagem ecossistêmica pode contribuir com o nutricionista na construção de suas estratégias, a fim de promover "a qualidade de vida como resultado da singularidade (identidade própria) e do apoio mútuo entre (reciprocidade) as dimensões de mundo"17, p.106. Nesse processo, Pilon ${ }^{18}$ argumenta que o desenvolvimento de relações humanas por meio de dinâmicas de grupos propicia interações genuínas entre as pessoas, possibilitando a construção de novas formas de estar-no-mundo, propiciadoras de uma melhor qualidade de vida, tal como aludido na citação anterior.

No cenário do estudo, o NASF tem se conformado como uma equipe de profissionais especialistas inserida na estratégia, desenvolvendo seu trabalho de forma pouco articulada às equipes de SF. Assim, as concepções acerca do papel do NASF, bem como as dificuldades, potencialidades e expectativas encontradas em seus itinerários, têm possibilitado a construção de contornos diversos do processo de trabalho das equipes NASF, os quais, longe de se limitarem ao arranjo pretendido pelo apoio matricial, abrangem diferentes modos de 'estar' na ESF.

Vale ainda ressaltar a existência de fragilidades teórico-conceituais acerca das políticas de saúde nas quais esses profissionais se inserem. A 
fala abaixo ilustra tal afirmação, uma vez que se refere à ESF de maneira destoante das concepções constitutivas dessa estratégia:

Trabalha com a prevenção, e o tratamento não em longo prazo, uma coisa assim mais rápida. E se for tratamento em longo prazo já é atenção secundária, os hospitais. E eu vejo que hoje não, as pessoas estão procurando mais porque têm algum problema que não é para ter (E8).

Os pressupostos, princípios e discussões acerca das políticas de saúde são elementos que poderiam constituir-se potenciais indutores de uma postura reflexiva acerca do papel do nutricionista na construção do SUS, indicando a presença de uma práxis congruente com esse novo espaço. Tal achado corrobora a fragilidade da formação política da categoria ${ }^{11,12}$ e a baixa concentração das disciplinas direcionadas ao SUS e à ESF nos currículos de graduação ${ }^{14}$, situação que, não obstante, vem sofrendo significativas mudanças tensionadas pela inserção do nutricionista nas políticas sociais. É importante ressalvar o pouco tempo de inserção dos participantes na ESF, bem como o perfil de formação predominante no momento histórico no qual eles se graduaram $^{14}$.

\section{Um fazer preventivista}

O projeto preventivista, voltado à prevenção de doenças e suas complicações, e tendo como núcleo de atuação profissional as atividades de educação em saúde ${ }^{19}$, assume caráter central nos discursos acerca do lugar do nutricionista na ESF. Em consonância com o perfil epidemiológico e nutricional brasileiro, os participantes veem como seu principal atributo a prevenção e tratamento de doenças crônicas associadas à alimentação, materializados principalmente mediante atividades educativas de caráter coletivo.

[...] Então, eu vejo o nutricionista inserido mais nessa parte de prevenção mesmo, em grupos que possam orientar a questão da diabetes, da hipertensão [...] onde a alimentação é a base (E8).
[...] A minha prioridade é exatamente para a prevenção e o tratamento das doenças, no que diz respeito à parte da alimentação (E5).

De fato, a magnitude assumida pelas doenças crônicas no perfil de morbimortalidade da população brasileira apresenta-se como um desafio importante a ser enfrentado pelo SUS. Nessa perspectiva, a inserção dos nutricionistas no NASF inclui, entre seus principais objetivos, fomentar o desenvolvimento de ações como as mencionadas no âmbito da APS 6 .

Os excertos transcritos sustentam a importância do nutricionista no enfrentamento do problema, porém apresentam uma visão abreviada acerca da condução do cuidado em saúde pretendido na ESF bem como do fazer da categoria. Percebe-se a vinculação de suas atribuições ao aspecto da doença e ao recorte alimentação, reverberando em uma atenção à saúde fragmentada, a qual intenta ser reeditada por meio da estruturação da ESF e da inserção do NASF.

Diante da complexidade dos problemas de saúde enfrentados na atualidade, o projeto preventivista ganha outros contornos.

[...] A gente também trabalha com isso, em relação ao social. [...] Não vá por esse caminho! Porque realmente quando a gente trabalha com drogas, com HIV... (E5).

[...] a nutrição no NASF, ela não trabalha só a nutrição, a gente trabalha [...] temas de nutrição, de psicologia, de atividade física, de todas as áreas. A gente trabalha artesanato também [...] na verdade a prevenção é de maneira geral (E7).

Apesar de aludirem à concepção de que a saúde transcende o âmbito da assistência à saúde, embrenhando-se na totalidade do existir do indivíduo, as falas remetem à ideia de prevenção como prescrição. Consoante os discursos, é possível supor que a finalidade da atuação consiste mais em normalizar a vida das pessoas do que configurar-se em um fazer no qual os saberes, 
práticas e recursos disponíveis estejam a serviço e potencializem a construção autobiográfica da saúde do usuário.

Cabe assinalar que o emprego de "usuário" como conceito neste artigo se alinha a um posicionamento ético-político segundo o qual, em lugar de alvo passivo de ações/intervenções técnicas ou mero consumidor de serviços e produtos, os sujeitos que buscam atenção se inserem no campo da saúde como cidadãos portadores de direito, cujo olhar deve ser considerado em avaliações, com vistas a julgar o mérito de um programa, serviço ou ação ${ }^{20}$.

A perspectiva da normalização da vida dos usuários remete à discussão acerca da biopolítica, empreendida inicialmente por Foucault. Autores como Neto et al. ${ }^{21}$, dialogando com ele, afirmam que a biopolítica permitiu o ajustamento das formas de vida das populações aos processos econômicos. Heckert ${ }^{22}$ menciona a biopolítica como uma tecnologia de poder que tem como objeto de atuação a população, centrando na vida do homem enquanto espécie e incidindo sobre os fenômenos humanos. Para a autora, essa tecnologia intensifica as técnicas disciplinares, voltadas ao controle dos corpos, tornando-os dóceis e produtivos.

Os discursos das entrevistadas evidenciam a normatização dos modos de viver em sociedade como parte do fazer da categoria. A ideia de controle trazida em muitas falas vai ao encontro da reflexão de Rose $^{23}$, quando afirma que o campo da biopolítica, no século 20, adquire outra conformação. Nesta, o foco incide mais no controle das capacidades vitais dos indivíduos do que propriamente na doença, produzindo uma 'política da vida' e seus desdobramentos disciplinares. Ademais, Pedroza ${ }^{24}$ argumenta que o nutricionista, tendo como recorte do campo biomédico a prescrição dietética, atua com instrumentos de poder e controle de comportamentos, alinhados à manutenção da ordem biopolítica. Corroboram esta argumentação elementos presentes na discussão acerca do desenvolvimento da profissão no Brasil, encontrando-se esta atrelada a estratégias de controle da lógica capitalista ${ }^{11,12}$.
A racionalidade biomédica prevalece, nas falas, como principal atributo estruturador das ações educativas em saúde, em conformidade com a óptica da prevenção de doenças, sendo central na atuação da categoria. As atividades voltadas para esse fim direcionam-se à otimização dos recursos financeiros, priorizando o consumo de uma alimentação saudável, no confronto com outras perspectivas de materializar o Direito Humano à Alimentação Adequada (DHAA). Aliás, é oportuno pontuar a ausência da referência a esse direito nos discursos acerca do lugar do nutricionista na ESF.

A argumentação em prol da mudança das práticas alimentares centra-se nos nutrientes e, embora transcenda a explicação unicausal, observa-se que a ampliação do olhar para o comportamento alimentar das comunidades é descontextualizada da complexidade que a perpassa:

O meu papel é de orientar, é de esclarecer [...] se é para você tomar um copo de refrigerante, que é um alimento que não tem na composição dele nada de bom à sua saúde, é preferivel você tomar um copo de suco [...] Meu papel é orientar, esclarecer, ele vai comer o que quer, mas ele está sabendo! [tom enfático, silêncio] (E6).

As pessoas sabem da necessidade de elas comerem as frutas e as verduras, mas elas não comem. Então, a gente trabalha muito mostrando: não sobra dinheiro para o refrigerante? [...] a gente tenta mostrar o custo-benefício (E7).

Os discursos remontam aos primórdios da educação nutricional, a qual, pensada em um contexto de escassez de alimentos no período pós-guerra, tinha a incumbência de qualificar o consumo alimentar de populações empobrecidas, buscando a otimização de recursos ${ }^{25}$. Desse modo, o papel assumido pelos nutricionistas em persuadir a população para a realização de trocas alimentares, propiciadoras de melhor custo-benefício, contribui para escamotear os aspectos 
fundamentais envolvidos na gênese da problemática alimentar e nutricional contemporânea. Essa ideia remonta à discussão de Bosi ${ }^{26}$, a qual permanece atual quanto a essa concepção e às práticas dela decorrentes. A autora pontua ainda que inicialmente a categoria foi concebida como um profissional com habilidades técnicas capazes de neutralizar os conflitos sociais potencialmente manifestos na área da nutrição.

A vinculação da equipe de SF a um território, fundamento basilar da APS, torna premente que questões alimentares e nutricionais sejam concebidas a partir do seu enraizamento no contexto sociocultural. Ademais, o DHAA como imperativo ético das políticas públicas impele à realização de abordagens mais abrangentes do que meras substituições alimentares em prol da minimização de riscos à saúde, direcionando as ações para um enfoque no qual a alimentação é vinculada à questão da cidadania. Portanto, os profissionais de SF, ambicionando o cuidado integral aos agravos relacionados à alimentação e nutrição, necessitam pensar intervenções que considerem os condicionantes e determinantes materiais e imateriais, objetivos e subjetivos da alimentação e nutrição, tanto no plano individual quanto coletivo.

\section{O escopo do atendimento ambulatorial}

É importante pontuar o escopo assumido pelo atendimento individual no fazer do nutricionista. Embora os entrevistados admitam não ser essa a sua principal atribuição, conforme o disposto na proposta oficial ${ }^{5,6}$, tal atividade apresenta-se ainda como uma prática majoritária na ESF.

O carro-chefe daqui é atendimento, nem só da minha parte, não. Mas da parte dos outros profissionais também. Mas eu queria muito mais fazer o que o NASF prega, que é a promoção da saúde [...] justamente estar prevenindo e dando palestras (E4).
Tal característica relaciona-se à necessidade de responder à demanda da equipe de SF e da própria comunidade, como se isso favorecesse a legitimidade da proposta NASF e de seu próprio fazer. Ademais, percebe-se em alguns discursos certa passividade diante da forma de eleição dos casos encaminhados por parte da equipe, sendo ausentes atitudes proativas favorecedoras de discussões acerca desse aspecto.

Nessa perspectiva, também é interessante observar que a produção de valores e produtos relacionados aos ideais de saúde e beleza e à medicalização da vida, veiculados na sociedade contemporânea, perpassa a construção do fazer do nutricionista no NASF. O contato com um nutricionista e a prescrição dietética representam atualmente uma das aspirações de consumo da população adscrita pela ESF:

[...] a nutrição está muito em alta, né? A mídia está investindo muito na tal de alimentação saudável. Então, hoje se você fala que é nutricionista, a primeira coisa que o povo faz é "passa uma dieta pra mim" [...] Eu fui apresentada a um grupo, eles disseram "essa aqui é a doutora nutricionista". Todo mundo já arregala os olhos e já vem falar comigo (E3).

Em alguns discursos, essa necessidade da população é encarada positivamente pelos profissionais, como uma forma de valorização da categoria e maior reconhecimento social. Em outros, representa um desafio, já que os nutricionistas não consideram sua função atuar em casos "apenas" estéticos, corroborando o entendimento de que o papel da categoria na ESF é prioritariamente prevenir ou mesmo tratar doenças. O "apenas" é colocado entre aspas tendo em vista o potencial papel adoecedor que a difusão desses valores e ideais exerce nas comunidades, ao propagarem a padronização de um modo de viver muitas vezes incongruente com as condições materiais. Essa e outras contradições apresentam-se como mais um desafio importante a ser mediado durante a construção do fazer do nutricionista na ESF. 


\section{Outros lugares e devires nesse novo espaço}

A referência aos programas e políticas de alimentação e nutrição surge para localizar o nutricionista na ESF:

Existe a politica de alimentação e nutrição [...] aí já tem o lugar do nutricionista trabalhando em diversos programas ligados a essa política. E é isso! Está mais do que claro o lugar do nutricionista na equipe. Na segurança alimentar $e$ nutricional. Em várias coisas, estar vendo a questão do consumo alimentar, disso a coisas maiores. Então, assim: está mais do que claro que existe o lugar do nutricionista sim. Falta ele ser melhor habitado. Melhor trabalhado! (E9) (grifo nosso).

Além da participação na execução de programas federais, a fala permite depreender que o lugar aludido refere-se mais a um espaço de atuação virtual, um devir, conformado pela institucionalização do enfrentamento da problemática alimentar e nutricional pelo Estado brasileiro, do que propriamente a um lugar consolidado na prática do nutricionista. Interessante observar que, ao mesmo tempo que a profissional afirma estar 'mais do que claro' esse lugar, as palavras parecem Ihe faltar para relatar a correspondência deste em sua prática cotidiana.

Ainda que de modo minoritário, a perspectiva do apoio matricial foi relatada como núcleo fundamental da inserção do nutricionista na ESF. O discurso abaixo ressalta o papel desse profissional no compartilhamento de seus saberes específicos com a equipe de Saúde da Família (SF), aspecto que configura em parte o apoio matricial ${ }^{6,7}$.

[...] como eu posso contribuir muito? $\dot{E}$ na questão da educação em saúde, eu vejo como o principal foco. Educação em saúde do usuário, do ACS, do próprio médico, da própria enfermeira que tem uma visão diferente do nutricionista. Para isso que existem as equipes, porque, senão, não precisava (E1).

A incorporação de diferentes categorias na ESF possibilita avançar na construção do trabalho interdisciplinar, uma vez que insere diversas competências e habilidades específicas que, articuladas umas às outras, potencializam a efetivação de abordagens pautadas pela assistência integral. Nesse cenário, a interdisciplinaridade configurar-se-ia como uma mediadora entre as disciplinas, as quais se relacionariam por meio de um suporte conceitual comum e objetivos e responsabilidades de trabalho compartilhadas ${ }^{27}$. Entretanto, há que se considerar que essa articulação deve ser construída diariamente entre profissionais mediante práticas concretas, as quais são perpassadas por inúmeros obstáculos, sejam conceituais, subjetivos ou estruturais ${ }^{7}$, que necessitam ser explicitados e cuidados durante a construção do trabalho em equipe na ESF.

Nesse contexto, a inserção na ESF permite um alargamento das possibilidades de atuação para além das competências específicas, propiciando a assunção de responsabilidades compartilhadas entre equipe de SF e NASF no que se refere às questões sanitárias mais prevalentes. Assim, a dinâmica de trabalho e a incorporação de novos saberes exigidos pela inserção no NASF são colocadas no contexto do estudo como aspectos motivadores da atuação na ESF:

$$
\begin{aligned}
& \text { O nutricionista do NASF não trabalha só } \\
& \text { com nutrição [...] Por exemplo, eu tenho } \\
& \text { que estudar DST, hanseníase [...] Acho que } \\
& \text { o profissional do NASF, ele fica com o } \\
& \text { horizonte assim bem amplo, você tem que } \\
& \text { saber um pouco de tudo [...] Até porque, } \\
& \text { se você for com aquela visão muito fe- } \\
& \text { chada, especialista: - 'Meu problema aqui } \\
& \text { é obesidade, hipertensão e diabetes', não } \\
& \text { é assim. Você tem que atuar em todos os } \\
& \text { campos (E1). }
\end{aligned}
$$

As visões predominantes nos relatos sobre o lugar do nutricionista contribuem para germinar a reflexão acerca do que tem se configurado como núcleo e campo de atuação da categoria no NASF. Tal como pensado por $\mathrm{Campos}^{28}$ (p.222), "o nú- 
cleo demarcaria a identidade de uma área de saber e de prática profissional; e o campo, um espaço de limites imprecisos onde cada disciplina e profissão buscariam em outras, apoio para cumprir suas tarefas teóricas e práticas".

Finalmente, é relevante ressaltar iniciativas de cuidado mais abrangentes entre o grupo, congruentes com os princípios da humanização e integralidade. Nesses relatos, as profissionais privilegiam o encontro com o usuário, considerando-o em sua singularidade e historicidade, construindo espaços de escuta e acolhimento das demandas:

[...] você usa o lado afetivo também, não só o lado técnico [...] você sente quando aquela pessoa está precisando de uma escuta... Então você tem que conhecer a história da pessoa para saber onde é que você vai ajudar ela [...] não é uma coisa que eu sei, não. Eu estou aprendendo, entendeu? [risos] (E1).

A assunção da perspectiva do usuário como central na condução do cuidado, contextualizando-o em seu modo de viver, coaduna-se com a compreensão de homem pretendida pelo princípio da integralidade, oposta a uma visão reducionista e fragmentadora22,29. Apesar de muitos discursos evidenciarem uma atuação focada majoritariamente na dimensão técnica da nutrição, no discurso dos entrevistados há elementos que remetem à ESF como um espaço possibilitador de um contato mais próximo com as pessoas, sendo tal aspecto colocado como um fator que diferenciaria a área do nutricionista das demais. Os discursos comportam uma espécie de satisfação dos entrevistados, decorrente do contato com os usuários, remetendo à ideia de que a ESF Ihes permitiria um resgate de dimensões condutoras à humanização de si mesmos enquanto profissionais, ampliando o sentido das ações.

\section{O N CLUS Ã O}

Consoante o enfoque compreensivo, o intuito desta pesquisa não poderia ser apresentar reflexões fechadas nem respostas conclusivas sobre o fenômeno recortado, mas antes compartilhar um caminho percorrido em busca do entendimento do ainda incipiente lugar do nutricionista no NASF, na perspectiva deles próprios, incitando novas investigações acerca das problemáticas aqui levantadas - sobretudo, considerando ser este um espaço ainda muito recente. Tampouco foi o intuito deste trabalho, em se tratando de uma pesquisa fundamentada na tradição qualitativa, pretender generalizações ao modo do pensamento probabilístico-quantitativo. Contudo, com base no que os investigadores no campo qualitativo denominam transferabilidade, é possível, sob certas condições, estender os resultados obtidos em determinados contextos a outros cujos significados sejam similares, sem que isso dependa do número de casos estudados, mas sim da compreensão profunda de cada fenômeno, devidamente contextualizado.

Os achados revelam posturas profissionais pouco alinhadas aos princípios e diretrizes do SUS e das políticas de SAN. Nesse contexto, as práticas ancoradas apenas em manejo de nutrientes, fundadas em "verdades científicas", entendidas na perspectiva da biomedicina, derivam intervenções incoerentes e potencialmente injustas ante os sofrimentos e contradições advindos dos modos contemporâneos de produção, comercialização, publicidade, acesso e consumo de alimentos.

A abordagem reducionista das questões emergentes no cenário alimentar moderno, ao invés de coprodutora de saúde, pode induzir iatrogenias nos usuários dos serviços que, com suas "escolhas" alimentares - grosso modo condicionadas por aspectos econômicos e culturais que transcendem a vontade e decisão individual, em uma perspectiva de senso comum -, podem sofrer silenciosamente as contradições resultantes desse cenário e ainda sanções, como a culpabilização.

Todavia, ao lado dessa postura tantas vezes constatada na literatura científica, foi possível apreender iniciativas e motivações orientadas por outros modos de conduzir o cuidado alimentar e 
nutricional na ESF, coerentes com os princípios da humanização e integralidade. Assim, considera-se ser de extrema relevância a proatividade do nutricionista na luta pela concretização do DHAA no cotidiano da ESF, alinhavando esta a todas as práticas de saúde por ele construídas, de modo a conceber esse espaço não apenas como mais um lugar, mas um novo lugar, potencializador de uma práxis alinhada ao ideário do SUS.

\section{A GRADECIMENTOS}

Ao Conselho Nacional de Desenvolvimento Científico e Tecnológico e à Fundação Cearense de Desenvolvimento Científico e Tecnológico pelo apoio financeiro ao LAPQS/UFC e concessão de bolsas à linha de pesquisa coordenada pela segunda autora, junto à Pós-Graduação em Saúde Coletiva da Universidade Federal do Ceará, iniciativa da qual deriva, dentre outros produtos, o presente artigo.

\section{COLABORADORES}

DCM RODRIGUES participou da concepção e desenho do estudo, construção e processamento das informações e redação do manuscrito. MLM BOSI participou do desenho do estudo, processamento e categorização das informações, redação do manuscrito e revisão crítica da versão final do artigo.

\section{REFERÊ N CIAS}

1. Gil CRR. Atenção primária, atenção básica e saúde da família: sinergias e singularidades do contexto brasileiro. Cad Saúde Pública. 2006; 22(6):1171-81. doi: 10.1590/S0102-311X2006000600006

2. Giovanella L, Mendonça MHMD, Almeida PF. Saúde da família: limites e possibilidades para uma abordagem integral de atenção primária à saúde no Brasil. Cienc Saúde Colet. 2009; 14(3):783-94. doi: 10.1590/S1413-81232009000300014

3. Andrade LOM, Barreto ICHC, Bezerra RC. Atenção primária à saúde e estratégia saúde da família. In: Campos GWS, Minayo MCS, Akerman M, Drumond Júnior M, Carvalho YM, Organizador. Tratado de saúde coletiva. $2^{a}$ ed. São Paulo: Hucitec; 2009.
4. Brasil. Ministério da Saúde. Portaria $n^{\circ} 2.488$, de 21 de outubro de 2011. Aprova a Política Nacional de Atenção Básica, estabelecendo a revisão de diretrizes e normas para a organização da Atenção Básica, para a Estratégia Saúde da Família (ESF) e o Programa de Agentes Comunitários de Saúde (PACS). Brasília: Ministério da Saúde; 2011 [acesso 2011 nov 1]. Disponível em: <http://bvsms.saude. gov.br/bvs/saudelegis/gm/2011/prt2488_21_10_ 2011.html>.

5. Brasil. Ministério da Saúde. Portaria GM n 154, de 24 de janeiro de 2008. Cria os Núcleos de Apoio à Saúde da Família - NASF. Brasília: Ministério da Saúde; 2008 [acesso 2008 fev 2]. Disponível em: <http://bvsms.saude.gov.br/bvs/saudelegis/gm/ 2008/prt0154_24_01_2008.html>.

6. Brasil. Ministério da Saúde. Secretaria de Atenção à Saúde. Diretrizes do NASF: núcleo de apoio a saúde da família. Brasília: Ministério da Saúde; 2009 [acesso 2011 dez 13]. Disponível em: <http://189. 28.128.100/dab/ docs/publicacoes/cadernos_ab/ abcad27.pdf>.

7. Campos GWS, Domitti AC. Apoio matricial e equipe de referência: uma metodologia para gestão do trabalho interdisciplinar em saúde. Cad. Saúde Pública. 2007 [acesso 2010 jan 13]; 23(2):399-407. Disponível em: <http://www.scielo.br/scielo. php? script=sci_arttext\&pid=S0102-311X20070002000 $16 \& \operatorname{lng}=$ en \&nrm=iso\&tlng=pt>. doi: 10.1590/S 0102-311X2007000200016>.

8. Brasil. Ministério da Saúde. Portaria $n^{\circ} 4.279$, de 30 de dezembro de 2010. Estabelece diretrizes para a organização da Rede de Atenção à Saúde no âmbito do Sistema Único de Saúde (SUS). Brasília: Ministério da Saúde; 2010 [acesso 2010 dez 30]. Disponível em: <http://bvsms.saude.gov.br/bvs/ saudelegis/gm/2010/prt4279_30_12_2010.html>.

9. Recine $E$, Vasconcelos $A B$. Políticas nacionais e o campo da alimentação e nutrição em saúde coletiva: cenário atual. Cienc Saúde Colet. 2011; 16(1):73-9. doi: 10.1590/\$1413-81232011000100 011

10. Pádua JG, Boog MCF. Avaliação da inserção do nutricionista na Rede Básica de Saúde dos municípios da Região Metropolitana de Campinas. Rev Nutr. 2006; 19(4):413-24. doi: 10.1590/S141552732006000400001

11. Bosi MLM. Profissionalização e conhecimento: a nutrição em questão. São Paulo: Hucitec; 1996.

12. Vasconcelos FAG. O nutricionista no Brasil: uma análise histórica. Rev Nutr. 2002 [acesso 2010 jun 13]; 15(2):127-38. doi: 10.1590/S1415-52732002 000200001

13. Brasil. Ministério da Educação. Conselho Nacional de Educação. Resolução CNE/CES 5, de 7 de no- 
vembro de 2001. Institui diretrizes curriculares nacionais do curso de graduação em nutrição. 1. Brasília: Diário Oficial da União; 2001 [acesso 2011 jun 13]. Seção 1, p.3. Disponível em: <http://portal. mec.gov.br/cne/arquivos/pdf/CES05.pdf>.

14. Recine $E$, Gomes RCF, Fagundes AAF, Pinheiro ARO, Teixeira BA, Sousa JS, et al. A formação em saúde pública nos cursos de graduação de nutrição no Brasil. Rev Nutr. 2012; 2(1):21-33. doi: 10.1590/ S1415-52732012000100003

15. Bosi MLM. Pesquisa qualitativa em saúde coletiva: panorama e desafios. Cienc. Saúde Colet. 2012 17(3):575-86. doi: 10.1590/S1413-8123201200 0 300002

16. Brasil. Ministério da Saúde. Conselho Nacional de Saúde. Resolução $n^{\circ}$ 196, de 10 de outubro de 1996. Pesquisa envolvendo seres humanos. Comissão Nacional de Ética em Pesquisa. Brasília: Ministério da Saúde; 1996 [acesso 2011 nov 21]. Disponível em: <http://conselho.saude.gov.br/ web_comissoes/conep/aquivos/resolucoes/23_ out_versao_final_196_ENCEP2012.pdf>.

17. Pilon AF. Construindo um mundo melhor: abordagem ecossistêmica da qualidade de vida. RBPS. 2006 [acesso 2014 ago 15]; 19(2):100-12. Disponível em: <http://hp.unifor.br/pdfs_notitia/86 0.pdf>.

18. Pilon AF. Relações humanas com base em dinâmica de grupo em uma instituição de prestação de serviços. Rev Saúde Pública. 1987 [acesso 2014 ago 15]; 21(4):348-53. Disponível em: http://www. scielo.br/scielo.php?script=sci_arttext\&pid=S003489101987000400009>.

19. Arouca ASS. O dilema preventivista: contribuição para a compreensão e crítica da medicina preventiva [doutorado]. Campinas: Universidade Estadual de Campinas; 1975.

20. Esperidiao MA. Trad LAB. Avaliação de satisfação de usuários: considerações teórico-conceituais. Cad Saúde Pública. 2006; 22(6):1267-76. doi: 10.1590/ S0102-311X2006000600016
21. Neto JLF, Kind L, Barros JS, Azevedo NS, Abrantes TM. Apontamentos sobre promoção da saúde e biopoder. Saúde Soc. 2009 [acesso 2011 jan 23]; 18(3):456-66. Disponível em: <http://www.revistas. usp.br/sausoc/article/view/29615>.

22. Heckert ALC. Ética e técnica: exercício e fabricações. In: Pinheiro R, Mattos RA, Organizador. Cuidar do cuidado: responsabilidade com a integralidade das ações de saúde. Rio de Janeiro: Abrasco; 2008.

23. Rose N. The politics of life itself: Biomedicine, power and subjectivity in the Twenty-First Century. Oxford: Princeton University Press; 2007.

24. Pedroza RG. A nutrição social no Brasil: [mais] uma estratégia biopolítica? [dissertação]. Natal: Universidade Federal do Rio Grande do Norte; 2010.

25. Boog MCF. Educação nutricional: porque e para quê? J Unicamp. 2004 [acesso jun 2013]; 260:2-8. Disponível em: <http://www.unicamp.br/ unicamp/ unicamp_hoje/jornalPDF/ju260pag02.pdf>.

26. Bosi MLM. A face oculta da nutrição: ciência e ideologia. Rio de Janeiro: Espaço e Tempo; 1988.

27. Furtado JP. Equipes de referência: arranjo institucional para potencializar a colaboração entre disciplinas e profissões. Interface: 2007 [acesso 2011 out 15]; 22:239-5. doi: 10.1590/S1414-328320 07000200005

28. Campos GWS. Saúde pública e saúde coletiva: campo e núcleo de saberes e práticas. Cienc Saúde Colet. 2000 5(2):219-30. doi: 10.1590/S1413-812 32000000200002

29. Mattos RA. A integralidade na prática ou sobre a prática da integralidade. Cad Saúde Pública. 2004 20(5):1411-6. doi: 10.1590/S0102-311X2004000 500037 